\title{
PENGARUH KUALITAS PELAYANAN DAN PENGEMASAN DAYA TARIK WISATA TERHADAP KEPUTUSAN BERKUNJUNG SERTA DAMPAKNYA PADA KEPUASAN WISATAWAN DI MUSEUM NEGERI SONOBUDOYO YOGYAKARTA
}

\author{
Eryd Saputra \\ Politeknik Pariwisata Batam \\ Email: eryd@btp.ac.id \\ Ambiyar \\ Universitas Negeri Padang \\ Email: ambiyar@ft.unp.ac.id
}

\begin{abstract}
This research is conducted to determine effect of service quality and packaging of tourist attraction on visiting decisions and the impact on tourist satisfaction. This study uses a descriptive method with a quantitative approach where the results of this study are expected to provide useful strategic information in the management of the Sonobudoyo State Museum. The sample used in this study was 100 respondents taken based on the tourist population. In the discussion of this study, researchers used multiple regression analysis to determine the effect of independent variables on the dependent variable. The results of the study show simultan that there is a positive and significant influence between the variable quality of service and packaging of tourist attraction to visiting decisions and their impact on tourist satisfaction. The results of the analysis partially have the effect of variable service quality on tourist satisfaction that is not positive and significant.
\end{abstract}

Keywords: Quality of Service, Packaging of Travel Attractions, Decisions Visit, Satisfaction of Travelers.

\section{Pendahuluan}

Pariwisata merupakan salah satu sektor penggerak perekonomian Indonesia. Pemerintahan telah fokus menggarap sektor pariwisata, hal ini telihat dari anggaran yang diberikan lebih besar dari pada tahun-tahun sebelumnya. Pengembangan destinasi unggulan juga menjadi prioritas utama pemerintah dalam meningkatkan jumlah kunjungan wisatawan. Pengembangan destinasi yang dilakukan pemerintah 
pusat diterapkan oleh pemerintah provinsi dimana setiap provinsi berlomba-lomba mengembangkan dan mempromosikan daya tarik wisata daerah mereka. Salah satu provinsi di Indonesia yang menjadi pilihan wisatawan dalam melakukan aktivitas wisata yaitu Daerah Istimewa Yogyakarta (DIY) merupakan salah satu daerah tujuan wisata unggulan karena memiliki keunikan dan keberagaman, baik yang berbasis alam, budaya, ataupun daya tarik wisata buatan. Daya tarik wisata budaya di DIY menjadi prioritas dalam menciptakan atmosphere berwisata dimana salah satu destinasi yang wajib dikunjungi oleh wisatawan adalah sebuah museum dengan berbagai ciri khas peninggalan dan informasi seputar sejarah DIY. Museum merupakan salah satu daya tarik wisata budaya yang masih dikunjungi wisatawan dikarenakan terdapat berbagai museum yang menarik dan unik dengan kekhasan DIY. Keberagaman jenis museum yang terdapat di DIY menjadi perhatian pemerintah dalam melihat jumlah pengunjungnya yang masih jauh tertinggal dengan daya tarik wisata lain. Hal ini berbeda dengan museum-museum yang ada diluar negeri yang sangat ramai dikunjungi wisatawan.

Louvre merupakan museum yang berada di Prancis, dimana museum ini berhasil meraih kunjungan wisatawan sebesar 9,3 juta pada tahun 2014 (travel.kompas.com). Menurut Ketua Asosiasi Museum Indonesia (AMI), Putu Supadma Rudana, museum-museum yang ada di Indonesia harus segera direvitalisasi untuk menarik minat pengunjung. " Pertemuan ini diadakan untuk membahas dan berdiskusi mengenai masa depan museum agar lebih berkembang dan berkualitas dalam melayani masyarakat dan menjawab tantangan museum di skala internasional," (www.okezone.com). Pelayanan masih menjadi permasalahan yang harus diselesaikan dalam upaya peningkatan jumlah kunjungan ke museum. Selain pelayanan, permasalahan yang harus dibenahi pada museum antara lain: kompleksitas fungsi museum yang tidak diimbangi profesionalitas sumber daya manusia (SDM), belum optimalnya pemanfaatan teknologi informasi, peragaan 
koleksi museum yang tidak ditata secara modern, serta belum berkembangnya museum sebagai tempat yang nyaman dan menyenangkan bagi masyarakat, rendahnya kreativitas program dan aktivitas museum, kurang memadainya data dan informasi terkait dengan koleksi, serta belum diintegrasikannya museum dalam sistem pendidikan nasional kita, Ardiwidjaja (2008) dalam Jawa Pos (www.jawapos.com) dari kutipan diatas penataan masih menjadi kendala pada kemajuan museum dalam melayani pengunjung saat berwisata.

Penataan sangat erat hubungannya dengan pengemasan (packaging). Kemasan museum yang belum menarik, masih mendapat citra menyeramkan, kuno, dan membosankan. Hal ini yang membuat museum di Indonesia masih jauh tertinggal dengan negara lain. Perbaikan citra harus dilakukan oleh museum untuk menarik minat pengunjung, seperti pengemasan produk (packaging). Pengemasan produk dapat merubah citra museum yang telah melekat selama ini. Pengemasan produk dalam industri sangatlah penting, sebab kemasan akan membuat produk kita dikenal oleh konsumen. Daya tarik wisata merupakan produk pariwisata yang harus dikemas dengan baik, agar dapat menarik minat wisatawan untuk datang berkunjung. Museum Sonobudoyo yang terletak di pusat kota atau dekat dengan kawasan Malioboro yang menjadi destinasi utama para wisatawan berkunjung ke Yogyakarta. Lokasi museum yang strategis, tidak menjadi jaminan museum ini banyak dikunjungi oleh wisatawan. Tabel dibawah ini akan menjelaskan bahwa museum Sonobudoyo masih jauh tertinggal dari daya tarik wisata lainnya di kota Yogyakarta: 
Tabel 1. Statistik Kunjungan Wisatawan di Kota Yogyakarta

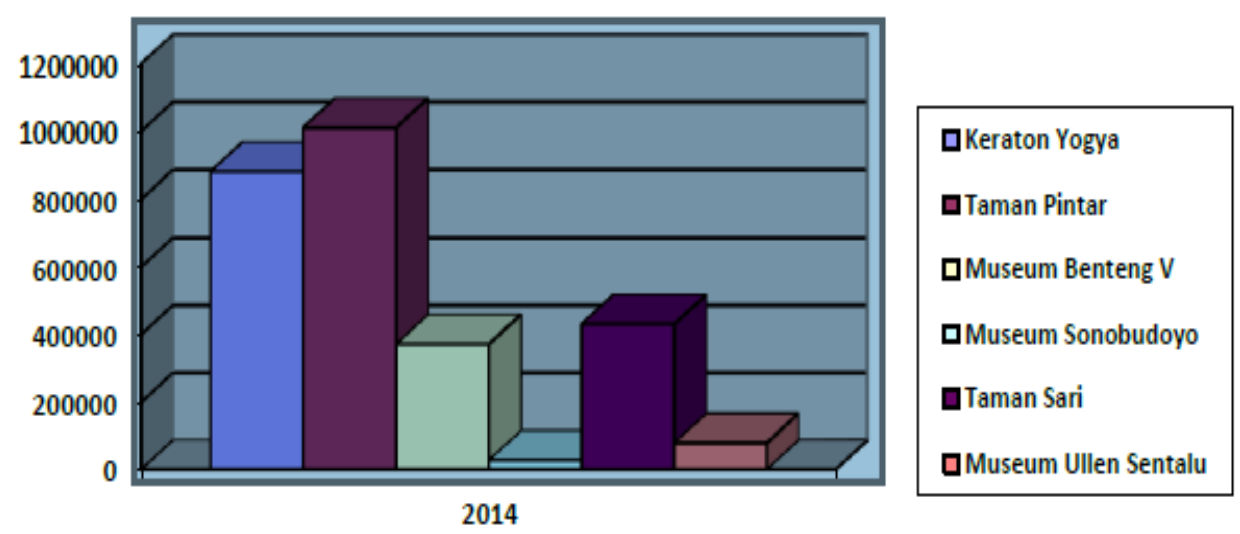

Sumber: (Buku Statistik Kepariwisataan Yogyakarta, 2015)

Museum Sonobudoyo memiliki koleksi yang sangat lengkap, potensi besar yang dimiliki oleh museum Sonobudoyo, seharusnya dapat menjadi magnet kuat dalam menarik minat orang untuk berkunjung, tetapi tidak demikian kenyataannya. Berdasarkan latar belakang masalah yang penulis paparan diatas, perlu adanya penelitian yang lebih lanjut untuk memberikan rekomendasi pada pihak pengelola museum Sonobudoyo. Penelitian ini diarahkan untuk mengukur pengaruh kualitas pelayanan dan pengemasan daya tarik wisata terhadap keputusan berkunjung serta dampaknya pada kepuasan wisatawan di museum negeri sonobudoyo Yogyakarta. Apabila kualitas pelayanan dan pengemasan daya tarik wisata tersebut mempengaruhi tingkat kunjungan, maka perlu dilakukan peningkatan agar dapat meningkatkan jumlah kunjungan wisatawan.

\section{Metode Penelitian}

Pada penelitian ini mengunakan analisis regresi berganda, yang bertujuan menerangkan pengaruh langsung dan tak langsung dari seperangkat variabel sebagai variabel penyebab terhadap seperangkat variabel lainnya yang merupakan varibel terikat. 


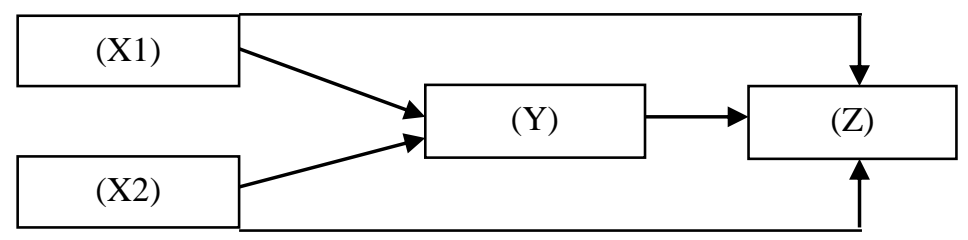

Gambar 1. Desain Penelitian yang Digunakan dalam Penelitian

Keterangan:

X1 = Kualitas Pelayanan

$\mathrm{X} 2=$ Pengemasan Produk Wisata

$\mathrm{Y} \quad=$ Keputusan Berkunjung

$\mathrm{Z} \quad=$ Kepuasan Wisatawan

Populasi yang digunakan untuk penelitian ini diambil dari pengunjung museum Sonobudoyo yang masuk ke dalam museum dan membeli tiket. Peneliti menggunakan rumus Slovin (1960), dalam Kusmayadi dan Sugiarto (2000) dimana dalam Penelitian ini akan melibatkan respon dari 100 sampel. Peneliti menggunakan Insedental sampling dalam mendapatkan sampel sebagai sumer data. Teknik analisis data yang digunakan adalah 1) analisis deskriptif, analisis tersebut digunakan untuk mendapatkan gambaran penyebaran hasil penelitian berdasarkan variable independent terhadap variable dependent; 2) regresi linier berganda, dilakukan dengan dua tahapan: analisis regresi langsung untuk mengetahui pengaruh kualitas pelayanan dan pengemasan produk wisata terhadap keputusan berkunjung dan Analisis regresi dengan variabel mediasi yang dilakukan dengan tujuan untuk mengetahui pengaruh kualitas pelayanan dan pengemasan produk wisata terhadap kepuasan wisatawan dengan mediasi variabel keputusan berkunjung; 3) uji F; 4) koefisien determinasi; 4) uji F; 5) uji t. 


\section{Hasil Dan Pembahasan}

\section{Hasil Penelitian}

\section{Analisis Regresi Linier Berganda}

Tabel 2 Hasil Analisis Regresi Berganda Coefficients

\begin{tabular}{|c|c|c|c|c|c|c|}
\hline \multirow{2}{*}{\multicolumn{2}{|c|}{ Model }} & \multicolumn{2}{|c|}{ Unstandardized Coefficients } & \multirow{2}{*}{\begin{tabular}{|l}
$\begin{array}{l}\text { Standardized } \\
\text { Coefficients }\end{array}$ \\
Beta \\
\end{tabular}} & \multirow[b]{2}{*}{$t$} & \multirow[b]{2}{*}{ Sig. } \\
\hline & & B & Std. Error & & & \\
\hline \multirow[t]{3}{*}{1} & (Constant) & 3.878 & 1.725 & & 2.248 & .027 \\
\hline & $\mathrm{X} 1$ & .095 & .034 & .336 & 2.775 & .007 \\
\hline & $X 2$ & .113 & .046 & .300 & 2.473 & .015 \\
\hline
\end{tabular}

a. Dependent Variable: Keputusan Berkunjung (Y)

Sumber: Data Primer yang diolah (2017)

$\mathrm{Y}=\mathrm{a} 1+\beta 1 \mathrm{X} 1+\beta 2 \mathrm{X} 2+\mathrm{e} 1$

$\mathrm{Y}=3.878+0,336 \mathrm{X} 1+0,300 \mathrm{X} 2+\mathrm{e} 1$

1. Kuliatas pelayanan (X1) memiliki pengaruh positif terhadap keputusan berkunjung.

2. Pengemasan produk wisata (X2) memiliki pengaruh positif terhadap keputusan berkunjung

Berdasarkan hasil analisis regresi linier berganda terhadap koefisiennya, terlihat bahwa variabel kualitas pelayanan mempunyai pengaruh yang lebih besar dibandingkan dengan variabel pengemasan daya tarik wisata.

Tabel 3 Hasil Analisis Regresi Berganda Coefficients

\begin{tabular}{|c|c|c|c|c|c|c|}
\hline \multirow{2}{*}{\multicolumn{2}{|c|}{ Model }} & \multicolumn{2}{|c|}{ Unstandardized Coefficients } & \multirow{2}{*}{\begin{tabular}{|l} 
Standardized \\
Coefficients
\end{tabular}} & \multirow[b]{2}{*}{$t$} & \multirow[b]{2}{*}{ Sig. } \\
\hline & & B & Std. Error & & & \\
\hline \multirow[t]{4}{*}{1} & (Constant) & 2.910 & 4.065 & & .716 & .476 \\
\hline & $\mathrm{X} 1$ & .110 & .082 & .162 & 1.342 & .183 \\
\hline & $\mathrm{X} 2$ & .305 & .108 & .338 & 2.820 & .006 \\
\hline & $\mathrm{Y}$ & .576 & .233 & .240 & 2.470 & .015 \\
\hline
\end{tabular}

a. Dependent Variable: Kepuasan Wisatawan (Z)

Sumber: Data Primer yang diolah (2017) 
$\mathrm{Z}=\mathrm{a} 2+\beta 3 \mathrm{X} 1+\beta 4 \mathrm{X} 2+\beta 5 \mathrm{Y}+\mathrm{e} 2$

$Z=2.910+0,162 X 1+0,338 X 2+0,240 Y+e 2$

1. Kualitas pelayanan memiliki pengaruh positif terhadap kepuasan wisatawan.

2. Pengemasan produk wisata memiliki pengaruh positif terhadap kepuasan wisatawan.

3. Keputusan berkunjung memiliki pengaruh positif terhadap kepuasan wisatawan.

Berdasarkan hasil analisis regresi berganda terhadap koefisiennya, terlihat bahwa variabel pengemasan produk wisata mempunyai pengaruh yang lebih besar dibandingkan dengan variabel kualitas pelayanan dan variabel keputusan berkunjung.

\section{Uji F}

\section{Uji F Model 1}

Tabel 4 Hasil Uji Anova Model 1

\begin{tabular}{|ll|l|l|l|l|l|}
\hline \multicolumn{2}{|l|}{ Model } & Sum of Squares & Df & Mean Square & F & Sig. \\
\hline 1 & Regression & 156.365 & 2 & 78.182 & 26.283 & $.000 \mathrm{a}$ \\
& Residual & 288.545 & 97 & 2.975 & & \\
& Total & 444.910 & 99 & & & \\
\hline
\end{tabular}

a. Predictors: (Constant), X2, X1

b. Dependent Variable: Keputusan Berkunjung

Sumber: Data Primer yang diolah (2017)

Pada tabel 4, dimana diperoleh nilai probabilitas (sig) adalah 0,00 dengan nilai F hitung sebesar 26.283. Maka disimpulkan bahwa variable kualitas pelayanan dan pengemasan produk wisata secara simultan berpengaruh positif terhadap keputusan berkunjung dan model dinyatakan fit. 


\section{Uji R2}

Tabel 5 Hasil Analisis Koefisien Determinasi Model Summary Model 1

\begin{tabular}{|l|l|l|l|l|}
\hline Model & R & R Square & Adjusted R Square & Std. Error of the Estimate \\
\hline 1 & $.593 \mathrm{a}$ & .351 & .338 & 1.725 \\
\hline
\end{tabular}

a. Predictors: (Constant), X2, X1

Sumber: Data Primer yang diolah (2017)

Pada tabel 5 hasil analisis koefisien determinasi, dapat disimpulkan sebagai berikut, hasil perhitungan estimasi regresi diperoleh nilai koefisien determinasi (adjusted $R$ square) sebesar 0,351 yang berarti bahwa variable yang diteliti memiliki pengaruh terhadap variable dependen sebesar 35,1\%. Sedangkan 64,9\% lainnya dipengaruhi oleh variabel lain yang tidak dijelaskan dalam model penelitian ini.

\section{Uji F Model 2}

Tabel 6 Hasil Uji Anova Model 2

\begin{tabular}{|ll|l|l|l|l|l|}
\hline Model & & Sum of Squares & Df & Mean Square & F & Sig. \\
\hline 1 & Regression & 1050.358 & 3 & 350.119 & 22.304 & $.000 \mathrm{a}$ \\
& Residual & 1507.002 & 96 & 15.698 & & \\
& Total & 2557.360 & 99 & & & \\
& &
\end{tabular}

a. Predictors: (Constant), Y, X2, X1

b. Dependent Variable: Kepuasan Wisatawan

Sumber: Data Primer yang diolah (2017)

Pada tabel 6 dimana diperoleh nilai probabilitas (sig) adalah 0,00 dengan nilai F hitung sebesar 22.304. Sehingga dapat disimpulkan bahwa kualitas pelayanan (X1), pengemasan produk wisata (X2) dan keputusan berkunjung (Y) secara simultan berpengaruh signifikan terhadap kepuasan wisatawan (Z). Oleh sebab model 2 dinyatakan fit. 


\section{Uji R2}

Tabel 7 Hasil Analisis Koefisien Determinasi Model Summary Model 2

\begin{tabular}{|l|l|l|l|l|}
\hline $\begin{array}{l}\text { Mode } \\
1\end{array}$ & R & R Square & Adjusted R Square & Std. Error of the Estimate \\
\hline 1 & $.641 \mathrm{a}$ & .411 & .392 & 3.962 \\
\hline
\end{tabular}

a. Predictors: (Constant), Y, X2, X1

Sumber: Data Primer yang diolah (2017)

Dari tabel 7 hasil analisis koefisien determinasi, dapat disimpulkan sebagai berikut, hasil perhitungan estimasi regresi diperoleh nilai koefisien determinasi (adjusted $R$ square) sebesar 0,411 yang berarti bahwa 41,1 \%. Sedangkan 58,9\% lainnya dipengaruhi oleh variabel lain yang tidak dijelaskan dalam model penelitian ini.

\section{Uji Hipotesis}

Hipotesis Umum

Terdapatnya pengaruh positif dan signifikan antara kualitas pelayanan dan pengemasan produk wisata terhadap keputusan berkunjung serta dampaknya pada kepuasan wisatawan di Museum Sonobudoyo Yogyakarta. Hal ini dapat dilihat pada tabel 6, yang mana probabilitas (sig) adalah 0,00 dengan nilai $\mathrm{F}$ hitung sebesar 22.304. Hal ini berarti bahwa Ha : diterima

\section{Pengujian Hipotesis Khusus Pertama}

Hipotesis pertama menguji pengaruh kualitas pelayanan terhadap keputusan berkunjung. Nilai sebesar 0,007 lebih kecil dari 0,05 yang berarti signifikan dan koefisien beta bernilai positif sebesar 0,336. Hal ini berarti bahwa Ha : diterima

\section{Pengujian Hipotesis Khusus Kedua}

Hipotesis kedua menguji pengaruh pengemasan produk wisata terhadap keputusan berkunjung. Nilai signifikansi sebesar 0,015 lebih kecil dari 0,05 yang 
berarti signifikan dan koefisien beta bernilai positif sebesar 0,300. Hal ini berarti bahwa Ha : diterima

Pengujian Hipotesis Khusus Ketiga

Hipotesis ketiga menguji pengaruh kualitas pelayanan terhadap kepuasan wisatawan. Nilai sig. 0,183 lebih besar dari nilai probabilitas 0,05 dengan nilai koefisien beta bernilai 0,162. Hal ini berarti bahwa Ha : ditolak

\section{Pengujian Hipotesis Khusus Keempat}

Hipotesis keempat menguji pengaruh pengemasan produk wisata terhadap kepuasan wisatawan. Nilai sig. 0,006 lebih kecil dari nilai probabilitas 0,05 dengan nilai koefisien beta bernilai 0338. Hal ini berarti bahwa Ha : diterima

Pengujian Hipotesis Khusus Kelima

Hipotesis kelima menguji pengaruh keputusan berkunjung terhadap kepuasan wisatawan. Nilai sig. 0,015 lebih kecil dari nilai probabilitas 0,05 dengan nilai koefisien beta bernilai 0338. Hal ini berarti bahwa Ha : diterima

\section{Uji Mediasi}

Pengujian Hipotesis Khusus Keenam

Tabel 8 Hasil Analisis Regresi Sederhana Coefficients

\begin{tabular}{|c|c|c|c|c|c|c|}
\hline \multirow{2}{*}{\multicolumn{2}{|c|}{ Model }} & \multicolumn{2}{|c|}{ Unstandardized Coefficients } & \multirow{2}{*}{ 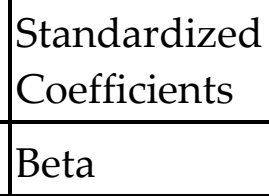 } & \multirow[b]{2}{*}{$\mathrm{t}$} & \multirow[b]{2}{*}{ Sig. } \\
\hline & & B & Std. Error & & & \\
\hline \multirow[t]{2}{*}{1} & (Constant) & 4.340 & 1.759 & & 2.467 & .015 \\
\hline & $\mathrm{X} 1$ & .158 & & .557 & 6.644 & .000 \\
\hline
\end{tabular}

a. Dependent Variable: Y

Sumber: Data Primer yang diolah (2017) 
Tabel 9 Hasil Analisis Regresi Berganda Coefficients

\begin{tabular}{|c|c|c|c|c|c|c|}
\hline \multirow{2}{*}{\multicolumn{2}{|c|}{ Model }} & \multicolumn{2}{|c|}{ Unstandardized Coefficients } & \multirow{2}{*}{ 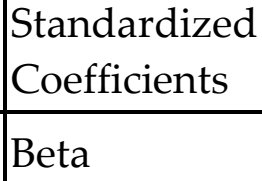 } & \multirow[b]{2}{*}{$\mathrm{t}$} & \multirow[b]{2}{*}{ Sig. } \\
\hline & & B & Std. Error & & & \\
\hline \multirow[t]{3}{*}{1} & (Constant) & 3.463 & 4.203 & & .824 & .412 \\
\hline & $\mathrm{X} 1$ & .254 & .066 & .374 & 3.826 & .000 \\
\hline & Y & .736 & .234 & .307 & 3.144 & .002 \\
\hline
\end{tabular}

a. Dependent Variable: $\mathrm{Z}$

Sumber: Data Primer yang diolah (2017)

Hubungan Antara Variabel Kualitas Pelayanan Dengan Kepuasan Wisatawan

Dimediasi Keputusan Berkunjung

Pengaruh tidak langsung dengan perhitungan 0,557 x 0,307 =0,171. Dari hasil perhitungan tersebut pengaruh tidak langsung sebesar 0,171 lebih kecil dari pengaruh langsung kualitas pelayanan terhadap kepuasan wisatawan sebesar 0,374. Kesimpulannya adalah bahwa keputusan berkunjung tidak memediasi pengaruh kuallitas pelayanan terhadap kepuasan wisatawan di Museum Sonobudoyo. Kesimpulannya adalah Ha: ditolak.

Pengujian Hipotesis Khusus Ketujuh

Tabel 10 Hasil Analisis Regresi Sederhana

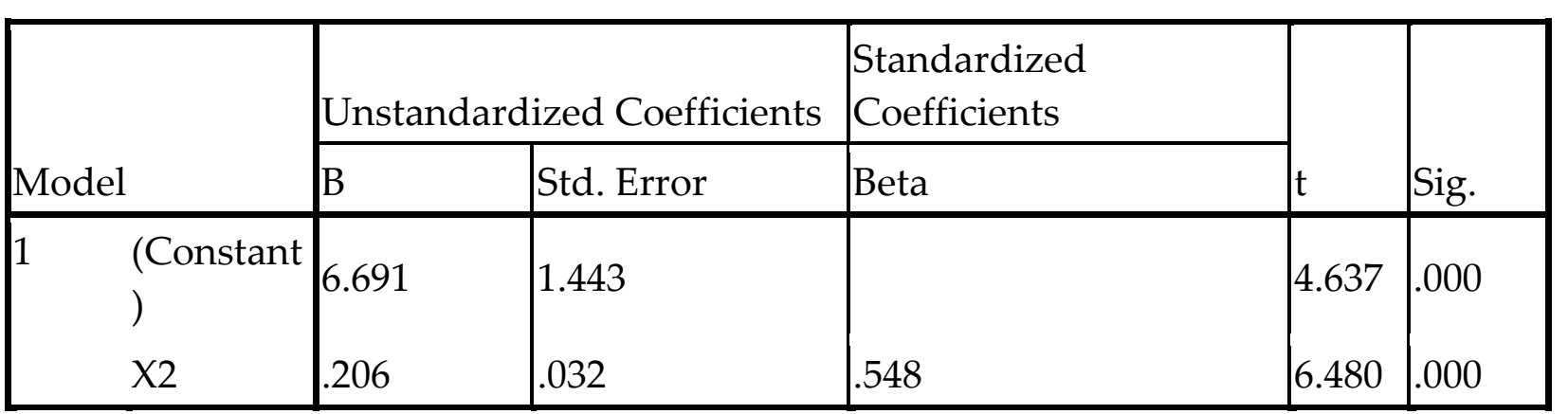

a. Dependent Variable: Y

Sumber: Data Primer yang diolah (2017) 
Tabel 11 Hasil Analisis Regresi Berganda

\begin{tabular}{|c|c|c|c|c|c|}
\hline \multirow[b]{2}{*}{ Model } & \multicolumn{2}{|c|}{ Unstandardized Coefficients } & $\begin{array}{l}\text { Standardized } \\
\text { Coefficients }\end{array}$ & \multirow[b]{2}{*}{$\mathrm{T}$} & \multirow[b]{2}{*}{ Sig. } \\
\hline & B & Std. Error & Beta & & \\
\hline $\begin{array}{ll}1 & \text { (Constan } \\
& \text { ) }\end{array}$ & 5.589 & 3.556 & & 1.572 & .119 \\
\hline $\mathrm{X} 2$ & .395 & .085 & .438 & 4.654 & .000 \\
\hline Y & .661 & .225 & .276 & 2.933 & .004 \\
\hline
\end{tabular}

a. Dependent Variable: Z

Sumber: Data Primer yang diolah (2017)

kepuasan wisatawan (Z). Hasil pengujian efek mediasi terlihat pada gambar dibawah ini:

Hubungan Antara Variabel Pengemasan Produk Wisata Dengan Kepuasan Wisatawan Dimediasi Keputusan Berkunjung

Pengaruh tidak langsung variabel pengemasan produk wisata terhadap kepuasan wisatawan melalui keputusan berkunjung diperoleh hasil perhitungan $0,548 \times 0,276=0,151$. Dari hasil perhitungan tersebut pengaruh tidak langsung sebesar 0,151 lebih kecil dari pengaruh langsung pengemasan daya tarik wisata terhadap kepuasan wisatawan sebesar 0,338. Kesimpulannya adalah bahwa keputusan berkunjung tidak memediasi pengaruh pengemasan produk wisata terhadap kepuasan wisatawan di Museum Sonobudoyo. Kesimpulannya adalah Ha: ditolak.

\section{Pembahasan}

\section{Pengaruh Kualitas Pelayanan dan Pengemasan Daya Tarik Wisata terhadap Keputusan Berkunjung serta Berdampak Pada Kepuasan Wisatawan}

Terdapatnya pengaruh positif dan signifikan antara kualitas pelayanan dan pengemasan daya tarik wisata terhadap keputusan berkunjung serta dampaknya pada kepuasan wisatawan di Museum Sonobudoyo Yogyakarta. Kualitas pelayanan 
dan pengemasan daya tarik wisata dapat mempengaruhi minat wisatawan untuk berkunjung ke museum Sonobudoyo, serta mempunyai dampak terhadap kepuasan wisatawan. Proses pencarian informasi yang dilakukan wisatawan menjadi proses awal, pada proses tersebut wisatawan akan memperoleh informasi tentang pelayanan dan pengemasan dari museum tersebut. Informasi yang diperoleh itu akan mempengaruhi wisatawan untuk berkunjung. Sejalan dengan penelitian terdahulu yang dilakukan oleh Mardhotillah dan Saino (2013) tentang pengaruh kualitas pelayanan di Baseball Food Court Universitas Negeri Surabaya dapat mempengaruhi keputusan pembelian konsumen, serta penelitian yang dilakukan oleh Nurhayati dan Rahman (2008) tentang pengaruh variasi dan kemasan produk terhadap keputusan pembelian teh kotak Ultrajaya hasil penelitianya menujukkan terdapatnya pengaruh yang positif dan signifikan dari variasi dan pengemasan produk terhadap keputusan pembelian. Hasil dari kunjungan wisatawan akan menghasilkan nilai yang mempengaruhi persepsinya. Nilai yang positif akan menghasilkan tingkat kepuasan yang tinggi dan nilai yang rendah akan menghasilkan tingkat kepuasan yang rendah. Berdasarkan hasil analisis, kepuasan yang diperoleh wisatawan yang berkunjung secara keseluruhan telah baik.

\section{Pengaruh Kualitas Pelayanan terhadap Keputusan Berkunjung}

Hasil dari analisis data menyatakan bahwa kualitas pelayanan berpengaruh positif dan signifikan terhadap keputusan berkunjung. Sejalan dengan pendapat Cronin, penelitian yang dilakukan oleh Mardhotillah dan Saino (2013) tentang pengaruh kualitas pelayanan di Baseball Food Court Universitas Negeri Surabaya dapat mempengaruhi keputusan pembelian konsumen. Proses pembelian yang lazim terdiri dari urutan kejadian berikut: pengenalan masalah, pencarian informasi, evaluasi alternatif, keputusan pembelian, dan prilaku pasca pembelian. Tahap keputusan pembelian, konsumen dihadapkan pada kondisi dimana ada niat untuk membeli yang dipengaruhi oleh faktor situasional yang tidak diantisipasi atau sikap orang lain yang akan mempengaruhi jenis keputusan pembeliannya Kotler dan 
Keller (2009). Pada proses pembelian diatas, proses pencarian informasi yang menjadi tolak ukur wisatawan akan berkunjung ke museum Sonobudoyo, informasi yang baik yang wisatawan dapatkan sangat mempengaruhi keputusan berkunjung tersebut.

\section{Pengaruh Pengemasan Produk Wisata terhadap Keputusan Berkunjung.}

Hasil analisis data bahwa pengemasan produk wisata berpengaruh positif dan signifikan terhadap keputusan berkunjung. Sejalan dengan penelitian terdahulu yang dilakukan oleh Nurhayati dan Rahman (2008) tentang pengaruh variasi dan kemasan produk terhadap keputusan pembelian teh kotak Ultrajaya. Hasil penelitiannya adalah terdapatnya pengaruh yang positif dan signifikan dari variasi dan pengemasan produk terhadap keputusan pembelian. Hasil analisis ini, didapati bahwa pengemasan daya tarik wisata memberi pengaruh positif dan signifikan terhadap keputusan berkunjung (pada hipotesis 2) di Museum Sonobudoyo. Hal ini menjadi sejalan dengan teori dan penelitian terdahulu yang dilakukan orang lain. Pengemasan daya tarik wisata menjadi penting baik yang berbasis alam, budaya, dan sejarah. Museum menjadi suatu wadah penempatan barang hasil budaya dan sejarah yang mempunyai kesan kuno, jadi dengan dilakukan pengemasan yang baik, citra yang museum selama ini akan berubah positif dan berdampak pada jumlah kunjungan yang akan meningkat.

\section{Pengaruh Kualitas Pelayanan terhadap Kepuasan Wisatawan}

Hasil analisis data bahwa kualitas pelayanan tidak berpengaruh positif dan signifikan terhadap kepuasan wisatawan. Cronin dkk (2000) mengemukakan bahwa persepsi kualitas layanan yang dirasakan merupakan tanggapan kognitif terhadap jasa yang ditawarkan, sedangkan kepuasan secara keseluruhan merupakan respon emosional yang didasarkan pada fenomena pandangan secara menyeluruh. Berdasarkan hasil analisis, didapati bahwa kualitas pelayanan tidak memberi pengaruh terhadap kepuasan wisatawan (pada hipotesis 3) di Museum 
Sonobudoyo. Hal ini menjadi sejalan dengan teori yang disampaikan sebelumnya, menyatakan bahwa kualitas pelayanan merupakan tanggapan dari hasil persepsi wisatawan setelah menggunakan jasa, hal ini berarti pelayanan yang dirasakan oleh wisatawan saat berkunjung belum optimal. Kepuasan wisatawan merupakan faktor penting dalam kemajuan daya tarik wisata. Pengelola museum harus lebih memperhatikan kualitas pelayanan yang diberikan, agar wisatawan merasa puas setelah melakukan kunjungan di museum Sonobudoyo.

\section{Pengaruh Pengemasan Produk Wisata terhadap Kepuasan Wisatawan}

Hasil analisis data bahwa pengemasan produk wisata berpengaruh positif dan signifikan terhadap kepuasan wisatawan. Sejalan dengan penelitian yang dilakukan pesoth (2015) yang mengahasilkan bahwa kualitas produk dan Packaging (pengemasan) berpengaruh signifikan terhadap kepuasan pelanggan. Berdasarkan hasil analisis pada penelitian ini, didapati bahwa pengemasan produk wisata memberi pengaruh terhadap kepuasan wisatawan (pada hipotesis 4) di Museum Sonobudoyo. Pengemasan produk wisata yang baik mendapat respon positif dari wisatawan, hal ini disebabkan pengemasan produk wisata menjadi penting untuk museum. Museum-museum yang ada diluar negeri memiliki pengemasan yang menarik, walaupun barang koleksi yang dipamerkan terkesan kuno namun pengemasan yang baik akan memberikan dampak kesan masa kini dan secara tidak langsung akan meningkatkan minat wisatawan untuk berkunjung.

\section{Pengaruh Keputusan Berkunjung terhadap Kepuasan Wisatawan}

Hasil dari analisis data membuktikan keputusan berkunjung berpengaruh positif dan signifikan terhadap kepuasan wisatawan. Berdasarkan hasil analisis ini, didapatkan bahwa keputusan berkunjung berpengaruh signifikan terhadap kepuasan wisatawan. Penelitian lain yang dilakukan Masruroh dan Suryadi (2010) menghasilkan bahwa strategi promosi dan keputusan pembelian yang berpengaruh positif tehadap kepuasan pelanggan. Berdasarkan hasil analisis pada penelitian ini, 
didapati bahwa keputusan berkunjung memberi pengaruh positif dan signifikan terhadap kepuasan wisatawan (pada hipotesis 5) di Museum Sonobudoyo.

\section{Kualitas Pelayanan Dimediasi oleh Keputusan Berkunjung terhadap Kepuasan Wisatawan}

Hasil analisis data membuktikan bahwa kualitas pelayanan tidak berpengaruh positif dan signifikan terhadap kepuasan melalui keputusan berkunjung. Hasil yang didapat berdasarkan analisis yang dilakukan, didapati bahwa secara langsung kualitas pelayanan dapat memberikan pengaruh terhadap kepuasan wisatawan. Analisis melalui mediasi keputusan berkunjung, kualitas pelayanan tidak memberikan hasil yang lebih tinggi dari hasil kualitas pelayanan secara langsung terhadap kepuasan wisatawan. Berdasarkan hasil analisis ini, didapat data bahwa kualitas pelayanan di Museum Sonobudoyo yang mempengaruhi kepuasan berkunjung. Namun jika secara bersama-sama kualitas pelayanan diuji, hasil yang didapat tidak signifikan.

\section{Pengemasan Produk Wisata Dimediasi oleh Keputusan Berkunjung terhadap Kepuasan Wisatawan}

Hasil analisis data membuktikan bahwa pengemasan daya tarik wisata tidak berpengaruh positif dan signifikan terhadap kepuasan melalui keputusan berkunjung. Hasil yang didapat berdasarkan analisis yang dilakukan, didapati bahwa secara langsung pengemasan daya tarik wisata dapat memberikan pengaruh terhadap kepuasan wisatawan. Analisis melalui mediasi keputusan berkunjung, pengemasan produk wisata tidak memberikan hasil yang lebih tinggi dari hasil pengemasan daya tarik wisata secara langsung terhadap kepuasan wisatawan. 


\section{Penutup}

\section{Simpulan}

Berdasarkan hasil penelitian, analisis data dan pengujian hipotesis yang telah dilakukan, maka dapat disimpulkan bahwa:

1. Terdapatnya pengaruh positif dan signifikan antara kualitas pelayanan dan pengemasan daya tarik wisata terhadap keputusan berkunjung serta dampaknya pada kepuasan wisatawan di Museum Sonobudoyo.

2. Kualitas pelayanan memberi pengaruh positif dan signifikan terhadap keputusan berkunjung di Museum Sonobudoyo.

3. Pengemasan produk wisata berpengaruh positif dan signifikan terhadap keputusan berkunjung di Museum Sonobudoyo.

4. Kualitas pelayanan tidak memiliki pengaruh positif dan signifikan terhadap kepuasan wisatawan di Museum Sonobudoyo.

5. Pengemasan daya tarik wisata memiliki pengaruh positif dan signifikan terhadap kepuasan wisatawan di Museum Sonobudoyo.

6. Keputusan berkunjung berpengaruh positif dan signifikan terhadap kepuasan wisatawan di Museum Sonobudoyo.

7. Keputusan berkunjung tidak memediasi pengaruh kualitas pelayanan terhadap kepuasan wisatawan di Museum Sonobudoyo.

8. Keputusan berkunjung tidak memediasi pengaruh pengemasan produk wisata terhadap kepuasan wisatawan di Museum Sonobudoyo.

\section{Saran}

Berdasarkan hasil penelitian, analisis data, serta pengujian hipotesis yang telah dilakukan oleh peneliti, maka saran yang diberikan pada Museum Sonobudoyo adalah sebagai berikut:

1. Melengkapi semua papan informasi koleksi dengan deskripsi singkat tentang objek yang dipamerkan dan harus mengunakan dua bahasa (Indonesia dan 
Inggris), hal ini disebabkan tidak semua wisatawan ingin dibantu oleh pemandu wisata.

2. Pengunaan teknologi dalam menyampaikan informasi (layar sentuh).

3. Mengunakan alat peraga atau alat yang dapat mengilustrasikan suatu informasi, contohnya peragaan pembuatan batik dengan robot manusia.

\section{Daftar Pustaka}

Cronin, J.J., Brady, M.K., Hult, G.T.M. (2000). Assessing the effects of quality, value and customer satisfaction on consumer behavioral intentions in service environments. Journal of Retailing.

Kotler dan Keller., 2009. Manajemen Pemasaran Jilid I. Edisi ke 13. Erlangga: Jakarta Kumayadi, Sugiarto, (2000). Metodologi Penelitian Dalam Bidang Pariwisata. Gramedia Pustaka. Jakarta

Madhotillah, I., Choirini, Saino, (2013) Pengaruh Kualitas Pelayanan terhadap Keputusan Pembelian Konsumen di Baseball Food Court Universitas Negeri Surabaya

Masruroh, Suryadi, W., 2010. Strategi Promosi, Diferensiasi dan Keputusan Pembeli pada Kepuasan Pelanggan, Universitas Jayabaya

Nurhayati, B.L. Yunia. R.A., (2008) Pengaruh Variasi dan Kemasan Produk terhadap Keputusan Pembelian Teh Kotal Ultrajaya (Survei Pada Mahasisiwa FPIPS Universitas Pendidikan Indonesia), Jurnal Strategic.

Pesoth, M.C., 2015. Pengaruh Kualitas Produk, Packaging, dan Brand Image Terhadap Kepuasan Pelanggan pada Perusahaan Rokok Dunhill di Kota Manado. Jurnal EMBA

Websites:

http://www.sonobudoyo.com/id/web/tentang/sejarah

http://travel.kompas.com , diunduh 17-06-2016 pukul 21.09).

(http://www.okezone.com/ unduh 14-06-2016, pukul 14.12)".

(http://www.jawapos.com/v, unduh 14-06-2016, pukul 14.11)" 


\section{Profil Penulis}

Eryd Saputra lahir di Bukittinggi pada tanggal 14 Februari 1988. Angkatan 2007 di Akademi Pariwisata Bunda Padang dengan jurusan Perhotelan (D3) dan dilanjutkan dengan S1 di Sekolah Tinggi Pariwisata Ambarrukmo Yogyakarta pada tahun 2011 denga jurusan Hospitality. Kemudian pada tahun 2013 melanjutkan kejenjang yang lebih tinggi yaitu S2 di Universitas Gadjah Mada jurusan Arsitektur Pariwisata, dan pada tahun 2015 melanjutkan juga S2 di Sekolah Tinggi Ilmu Ekonomi Pariwisata Indonesia. Pernah mengajar di Sekolah Tinggi Pariwisata Ambarrukmo Yogyakarta dan saat ini mengajar di Politeknik Pariwisata Batam. 